\title{
Effect of industrial crop Jerusalem artichoke on the micro-ecological rhizosphere environment in saline soil
}

\author{
Tianyun Shao ${ }^{1}$, Xiaohua Long $^{1}$, Xiumei Gao ${ }^{1}$, Manqiang $\mathrm{Liu}^{1}$, and Zed Rengel ${ }^{2}$ \\ ${ }^{1}$ Nanjing Agricultural University \\ ${ }^{2}$ The University of Western Australia
}

January 5, 2021

\begin{abstract}
Salinity is not only a threat to organisms and ecosystems, but also a major factor restricting the development of agricultural production. This study aimed to explore the modification effect of in-situ Jerusalem artichoke (genotype NY-1) cultivation on the rhizosphere micro-ecological environment in the saline-alkali region along the southeast coast of China. We analyzed the change of carbon and nitrogen in the saline soil from a microbial perspective, through the quantification of the area of root channels, rhizosphere secretions and soil microbiome (cbbL, cbbM and nifH). The root channels of NY-1 not only improved the physical structure of saline soil, but also provided a living space for microorganisms, afforded basic conditions for the optimization of the soil micro-ecological environment. In addition, rhizosphere secretions (from roots of NY-1 as well as microorganisms), such as carbohydrates, hydrocarbons, acids, etc., could be considered as a way to improve the saline-alkali soil habitat. NY-1 increased the diversity and abundance of autotrophic and nitrogen-fixing bacteria in saline soil (rhizosphere $>$ bulk soils), which should be a biological way to increase the amount of carbon and nitrogen fixation in soil. Moreover, some of the detected genera (Sideroxydans, Thiobacillus, Sulfuritalea, Desulfuromonas, etc.) participate in the carbon and nitrogen cycles, and in the biogeochemical cycle of other elements. In short, Jerusalem artichoke can improve not only the physical and chemical properties of saline-alkali soil, but also promote material circulation and energy flow in the micro-ecological rhizosphere environment of saline soils.
\end{abstract}

\section{Effect of industrial crop Jerusalem artichoke on the micro-ecological rhizosphere environment in saline soil}

Tianyun Shao ${ }^{1}$, Xiaohua Long ${ }^{1}$, Xiumei Gao ${ }^{1}$, Manqiang Liu ${ }^{1}$, Zed Rengel ${ }^{2,3}$

${ }^{1}$ College of Resources and Environmental Sciences, Nanjing Agricultural University, Nanjing 210095, China

${ }^{2}$ Soil Science and Plant Nutrition, UWA School of Agriculture and Environment, The University of Western Australia, 35 Stirling Highway, Perth WA 6009, Australia.

${ }^{3}$ Institute for Adriatic Crops and Karst Reclamation, Put Duilova 11, Split, Croatia

\section{Correspondence}

Xiaohua Long, College of Resources and Environmental Sciences, Nanjing Agricultural University, Nanjing 210095, China

E-mail: longxiaohua@njau.edu.cn (X.H. Long)

\section{Abstract}

Salinity is not only a threat to organisms and ecosystems, but also a major factor restricting the development of agricultural production. This study aimed to explore the modification effect of in-situ Jerusalem artichoke 
(genotype NY-1) cultivation on the rhizosphere micro-ecological environment in the saline-alkali region along the southeast coast of China. We analyzed the change of carbon and nitrogen in the saline soil from a microbial perspective, through the quantification of the area of root channels, rhizosphere secretions and soil microbiome $(c b b L, c b b M$ and nifH). The root channels of NY-1 not only improved the physical structure of saline soil, but also provided a living space for microorganisms, afforded basic conditions for the optimization of the soil micro-ecological environment. In addition, rhizosphere secretions (from roots of NY-1 as well as microorganisms), such as carbohydrates, hydrocarbons, acids, etc., could be considered as a way to improve the saline-alkali soil habitat. NY-1 increased the diversity and abundance of autotrophic and nitrogen-fixing bacteria in saline soil (rhizosphere $>$ bulk soils), which should be a biological way to increase the amount of carbon and nitrogen fixation in soil. Moreover, some of the detected genera (Sideroxydans, Thiobacillus, Sulfuritalea, Desulfuromonas, etc.) participate in the carbon and nitrogen cycles, and in the biogeochemical cycle of other elements. In short, Jerusalem artichoke can improve not only the physical and chemical properties of saline-alkali soil, but also promote material circulation and energy flow in the micro-ecological rhizosphere environment of saline soils.

\section{Keywords}

In-situ, microbial community, nitrogen fixation, secretions, root channel

\section{Introduction}

Due to global climate change and increasing population pressure, $33 \%$ of global soil is moderately to highly degraded through erosion, salinization, compaction, acidification, chemical pollution, and nutrient depletion, hampering soil functions and affecting food production (Abogadallah, 2010; Mao et al., 2016). Soil salinization causes damage not only to natural resources, but is also a major factor restricting the development of agricultural production and improving land-use efficiency, and is also a threat to organisms and ecosystems (Liu et al., 2018; Yu, Liu, Yang, Fan \& Zhou, 2018; Xia, Ren, Zhang, Wang \& Fang, 2019). Nevertheless, saline soils are widely distributed on the earth surface, covering approximately $7-8 \%$ of the world land area, making them a potentially important land resource (Shrivastava \& Kumar, 2015; Jiang et al., 2019).

In saline soils, salinity as well as alkalinity damage plant roots very seriously. Roots play an important role in plant growth. Roots extract nutrients and water from soil, and also exude a variety of organic and inorganic compounds into the rhizosphere soil. These exuded compounds change the chemistry and biology of the rhizosphere soil, making it significantly different from the bulk soil further away from roots (Marschner, 1995; Zhang, Li, \& Wang, 2007). Plants form a specific bacterial community structure in the rhizosphere soil through specific root exudation, and the secondary metabolites produced by some rhizosphere bacteria can promote plant growth (Sturz \& Christie, 2003). Furthermore, soil microbes also play an important role in maintaining the stability of ecosystems; they reflect the evolution of soil quality and are one of the indicators of the ecosystem health (Diacono \& Montemurro, 2010).

Jerusalem artichoke (Helianthus tuberosus L.), which belongs to the Asteraceae family, is a tuber-forming perennial distributed worldwide (Shi et al., 2011). Jerusalem artichoke is an excellent crop because it has strong resistance to abiotic stresses (drought, salinity, etc.), high photosynthetic efficiency, low fertilizer and water demand, great ecological restoration capacity, and high commercial value. It is easily grown in saline and alkaline soils, and it can also be used for soil and water conservation and fixing terraces and unstable sand (Long et al., 2010; Shao et al., 2019).

In this paper, we aimed to explore an in situ remediation technology using Jerusalem artichoke to improve the micro-ecological environment of saline soils varying in salinity in the southeast China. Through the quantification of the area of root channels, rhizosphere secretions and soil microbiome, the change of carbon and nitrogen in the saline soil was analyzed, and the modifying effect of Jerusalem artichoke cultivation on the micro-ecological rhizosphere environment in saline soil was elucidated.

\section{Materials and methods}

\subsection{Location and materials}




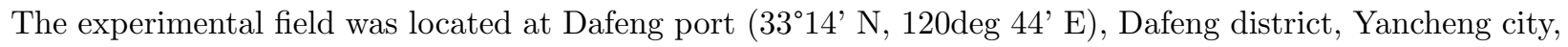
on the east coast of Jiangsu province.

The naturally saline experimental field $\left(\mathrm{pH}\right.$ 7.13-8.16) was divided based on different salt content $\left(\mathrm{g} \mathrm{salt} \mathrm{kg}^{-1}\right.$ soil) into high salinity (H, 4.1-5.0), moderate salinity (M, 2.9-3.9) and low salinity (L, 1.5-2.0). Different salinity levels had the same initial soil properties, and the soil (silty clay loam) was contained $65 \%$ silt and $18 \%$ clay.

The grass was mowed before plowing using a conventional moldboard plow. We selected Helianthus tuberosus L. cv. NY-1 (Su-Jian Jerusalem artichoke 200901) as a test material. NY-1 was planted with $0.6 \mathrm{~m}$ row spacing and $0.4 \mathrm{~m}$ intra-row spacing. No fertilizer and no irrigation was used during the 8-year period. Five replicate plots (5 x $5 \mathrm{~m}$ each) were planted in each area (Shao et al., 2019).

Soil was sampled in each replicate plot as follows: control soil (no Jerusalem artichoke planting, no human influence), rhizosphere soil (attached to the root system of Jerusalem artichoke) and bulk soil (away from Jerusalem artichoke roots). One composite sample (containing five soil cores) was taken from each replicate plot by the five-point sampling method (depth of 0-20 cm) using a soil auger $(6 \mathrm{~cm}$ diameter). All soil samples were packaged in separate sterile plastic bags; a portion of each soil sample was wrapped in tin foil, labeled, and snap-frozen in liquid nitrogen for subsequent DNA extraction and molecular analysis. The remaining soil was air-dried and passed through a $0.15-\mathrm{mm}$ sievs, then stored in a refrigerator at 4 for soil biological and chemical analyses (Lauber, Zhou, Gordon, Knight \& Fierer, 2010; Tatangelo, Franzetti, Gandolfi, Bestetti \& Ambrosini, 2014).

In addition, undisturbed soil columns were collected for the determination of root channels below the plants as well as in the inter-row positions. The sampling tools were rigid PVC pipes (inner diameter of $11 \mathrm{~cm}$, length of $40 \mathrm{~cm}$, wall thickness of $0.2 \mathrm{~cm}$ ) with a sharp edge at one end for driving into the soil profile. The extracted soil columns were wrapped in plastic for transport to the lab.

\subsection{Methods (See Appendix 1)}

\subsubsection{Root channels}

The area of root channels was characterized using a 64-row multi-slice spiral computed tomography CT scanner (Light Speed VCT, Jiangsu Provincial Hospital of Integrated Traditional Chinese and Western Medicine) (San, Caniego \& Garcia, 2017). The images (Figure A.1) were processed by running the "Intelligent Identification System for Pores in Saline Soil" V1.0 (2018SR074781). The minimum pixel area was set as 1, ie. the minimum identified root channel diameter was $0.298 \mathrm{~mm}$.

\subsubsection{Rhizosphere secretions}

We used ethyl acetate to extract the rhizosphere soil secretions and then profiled them using gas chromatography-mass spectrometry (GC-MS) (TSQ 8000TM Evo Triple quadrupole GC-MS, Thermo Fisher Scientific Co., Ltd., Shanghai, China) (Carvalhais et al., 2015; Liu et al., 2015).

\subsubsection{Illumina sequencing}

Specific primers with the barcode or fusion primers with dislocation of the bases were synthesized according to the designated sequencing regions. The primers for $c b b L, c b b M$ and nifH were $595 \mathrm{~F} / 1387 \mathrm{R}, 490 \mathrm{~F} / 974 \mathrm{R}$ and PolF/PolR, respectively. A TransGen AP221-02: TransStart FastPfu DNA polymerase $20 \mu \mathrm{L}$ reaction system was used (Alfreider, Vogt, Hoffmann \& Babel 2003; Tourova, Kovaleva, Sorokin \& Muyzer, 2010; Shao et al., 2019; Xu et al., 2020; Yue et al., 2020).

Data availability: The complete sequencing data sets have been deposited in the NCBI Sequence Read Archive (SRA) database under the accession number PRJNA555455.

\subsubsection{Statistical analysis and figure drawing}


Statistical analyzes were performed using Microsoft Excel 2007, SPSS Statistics 20.0 (IBM, Armonk, New York, USA) and R package vegan (version 2.5-5). Adobe Illustrator CC 2017 and R package ggplot2 (version 3.2.0) were used to draw figures (Oksanen et al., 2019; Kraemer, Ramachandran, Colatriano, Lovejoy \& Walsh, 2020).

The average value of all parameters was taken from the five replicates and the standard error was calculated. The data were analyzed by the multiple $t$-test (p[?]0.05). Correlation analysis used the Mantel test and Spearman's rank correlation coefficients (Guillot \& Rousset, 2013; Sedgwick, 2014). LDA Effect Size analysis (LEfSe) used the ANOVA and then the Wilcoxon rank sum test to analyze the differences between groups (threshold set to 0.05) (Kuffner et al. 2012; Yue et al., 2020).

\section{Results}

\subsection{Root channels}

The channel area in each type of soil was larger at a depth of $25 \mathrm{~mm}$ than in deeper layers (Figure 1A). At the depth of more than $225 \mathrm{~mm}$, the channel area was small, and there was no significant difference among various types of soil.

In the 0-200 $\mathrm{mm}$ and 200-400 $\mathrm{mm}$ soil layers, the channel area below the plants grown in the medium (M-UP) and low salinity soil (L-UP) was significantly larger than in the other types of soil (p[?]0.05) (Figure 1B). In soils with low and medium salinity, the difference in root channel area between soil under the plants and the inter-row soil was significant. However, in highly saline soils, the root channel area was similar between the soil under the plants (H-UP) and the inter-row soil (H-IR). In this study, the lowest ratio of the total channel area in 0-200 $\mathrm{mm}$ vs. 200-400 $\mathrm{mm}$ soil layer was in the inter-row on highly saline soil (H-IR, 4:3). A general trend of channel area in different soils at various soil depths was soil under the plants $>$ inter-row soil, as well as moderate and low salinity soil > high salinity soil (Figure 1B).

\subsection{Rhizosphere secretions}

The rhizosphere secretions detected in this study could be divided roughly into 15 types: hydrocarbons, acids/esters, alcohols, amines, ketones, nitriles, ammonium salts, aromatic hydrocarbons, hydrazines, amides, sulfonyls, oxides, ethers, aldehydes, and carbohydrates; however, the last seven types were detected only in the low salinity rhizosphere soils (L-R). Acids/esters were found in all soil samples and accounted for a relatively high proportion (43-83\%), except in the L-NR (30\%) and H-R soils (16\%). The other rhizosphere secretions widely present in all soil samples were hydrocarbons, but in a modest proportion, ranging from $1.07 \%$ to $9.6 \%$ (Figure $2 \mathrm{~A}$ ).

Alcohols were not detected in H-NR, and their relative proportion in the bulk soil was between $4.9 \%$ and $7.6 \%$, higher than in the rhizosphere soil $(0.24 \%$ to $3.2 \%)$. Amines were not detected in L-R, the two sample types with the highest relative proportions were L-NR (21\%) and H-NR (13\%), whereas CK soil had the lowest proportion $(0.39 \%)$. The relative proportion of ketones in CK was $22 \%$, which was significantly higher than in M-NR, L-NR and H-R $(2.9 \%, 0.24 \%$ and $3.4 \%$, respectively). Nitriles were detected only in highly saline soil, with relative proportions of $0.83 \%$ in H-NR and $0.19 \%$ in H-R (Figure 2A).

The six abundantly detected rhizosphere secretions were acids/esters, ammonium salts, amines, ketones, hydrocarbons, and alcohols (Figure 2A-D). For acids/esters in the bulk soil, the relative proportion increased with an increase in soil salinity, whereas it was mostly opposite in the rhizosphere soil. The relative proportion of ketones in CK soil (22\%) was significantly higher than in the other soil types, while amines was significantly higher in L-NR than in the other soil sample types. The relative proportion of alcohols in CK (7.6\%) was significantly higher than in the other soil sample types, and it was higher in the bulk soil than the rhizosphere soil (at medium and low salinity).

\subsection{Autotrophic and nitrogen-fixing bacteria}

Based on the Chao1 and the Shannon index, the community diversity of autotrophic bacteria containing $c b b L$ showed the order of bulk soil $>$ rhizosphere soil as well as of high salinity soil $>$ moderate salinity soil $=$ 
low salinity soil, and the community richness showed similar orders (Figure 3A). In the diversity information analysis, a total of 8 phyla, 11 classes, 28 orders, 32 families, and 59 genera of autotrophic bacteria containing cbbLwere detected, of which the 10 dominant genera wereg_Halorhodospira, g_Marichromatium, g_Thioalkalivibrio, g_unidentified, g_Alkalilimnicola, g_Thiobacillus, g_Rhodovulum, g_Cupriavidus, g_Hydrogenophaga, and $g_{-}$Ectothiorhodospira. The combined relative abundances of these 10 genera was generally above $90 \%$ in all soil samples, with the exception of the CK (58\%) and H-NR (83\%). The common dominant genera in the bulk soils wereg_Thioalkalivibrio and g_Marichromatium (Figure 3B, E).

In the LEfSe analysis of the autotrophic bacteria containing $c b b L$ (Figure $3 \mathrm{G}$ ), the statistically significant biomarkers were:o_Chromatiales, o_Rhodospirillales, o_Methylococcales ,o_Thermales, o_Burkholderiales , o_Rhizobiales, o_Synechococcales, o_Gallionellales ando_Rhodobacterales . (Figure 3G).

The community diversity of autotrophic bacteria containing $c b b M$ showed the order of rhizosphere soil $>$ bulk soil, which was the opposite of autotrophic bacteria containing $\operatorname{cbb} L(\mathrm{r}<-0.6)$ (Figure 3C, 5). The total of 29 phyla, 47 classes, 94 orders, 138 families, and 276 genera of autotrophic bacteria containing $c b b M$ were detected, with the 10 dominant genera beingunidentified, g_Halothiobacillus, g_Sideroxydans, g_Rhodopseudomonas, g_Thiobacillus, g_Sulfuritalea, g_Leptothrix, g_Magnetospirillum, g_Thiohalomonas, and g_Thiocystis; the sum of the relative abundance of the above 10 genera was around $80 \%$ in all soil samples. Dominant genera were $g_{-}$Halothiobacillus, g_Sideroxydans, g_Rhodopseudomonas, and g_Lepthrix in the rhizosphere soil, whereas g_Halothiobacillus, g_Thiobacillus, g_Sulfuritalea, and g_Thiohalomonas predominated in the bulk soil. In addition, the abundance of $g_{-}$Thiohororhabdus was lower in the rhizosphere soil $(0.44 \%)$ than the bulk soil (4.78\%) (Figure 3D, F).

In the LEfSe analysis of the autotrophic bacteria containing $c b b M$ (Figure $3 \mathrm{H}$ ), the statistically significant biomarkers were:o_Nitrospirales, o_Thermales, o_Halobacteriales, o_Chlorobiales, o_Acidithiobacillales, o_Thiotrichales, o_Chromatiales, o_Rhodospirillales, o_Methylococcales, o_Burkholderiales, o_Desulfovibrionales , ando_Pseudonocardiales .

The community diversity of nitrogen-fixing bacteria containing nifH showed the order of rhizosphere soil > bulk soil, which was the opposite of the autotrophic bacteria containing $c b b L(\mathrm{r}<-0.6)$ and similar to the autotrophic bacteria containing $c b b M(\mathrm{r}>0.6)$ (Figure 4A, 5). Total of 26 phyla, 52 classes, 100 orders, 163 families, and 309 genera containing nifH were detected, with the 10 dominant genera being unidentified, $g_{-}-$ Desulfuromonas, g_Geobacter, g_Bradyrhizobium, g_Azoarcus, g_Desulfovibrio, g_Geoalkalibacter, g_Azospirillum, g_Anaeromyxobacter, and g_Sinorhizobium. The relative abundances of these 10 genera were between $61 \%$ and $69 \%$ in the rhizosphere soil and $71 \%-76 \%$ in the bulk soil and CK. The dominant genera in CK and bulk were g_Desulfuromonas, g_Geoalkalibacter, g_Anaeromyxobacter, g_Pelobacter, g_Desulfobulbus, g-Pseudomonas, g_Ectothiorhodospira, g_Methylomonas, and g_Halorhodospira, whereas the dominat ones in the rhizosphere soil wereg_Geobacter, g_Desulfovibrio, g_Azospirillum, g_Sinorhizobium, g_Pseudacidovorax, g_Nostoc, g_Dechloromonas, g_Paraburkholderia, g_Rubrivivax, and g_Skermanella (Figure 4B, C).

A variety of unique nitrogen-fixing bacteria containing nifH in CK were showed in the LEfSe analysis (Figure 4D) to be statistically significant biomarkers:o_Chromatiales, o_Burkholderiales, o_Bacteroidetes, o_Rhizobiales, o_Oceanospirillales, o_Desulfobacterales, o_Xanthomonadales, o_Enterobacterales, and

o_Hydrogenophilales.

The data and the characteristics of important microorganisms are included in Table 1. Furthermore, there was a significant positive correlation between $c b b L$-containing autotrophic bacteria and amines (p[?]0.05), whereas nitrogen-fixing bacteria and $c b b M$-containing autotrophic bacteria each had highly significant negative correlations with nitriles (p[?]0.05) (Figure 5).

\section{Discussion}

\subsection{Root channels}

Soil porosity is a sine qua non of soil, and root channels are an important part of soil macropores in the 
soil system. Root distribution of Jerusalem artichoke was influenced by soil salt content, water content, $\mathrm{pH}$, and other factors (Hartle, Fernandez \& Nowak, 2006). In the present study, the root system of Jerusalem artichoke had the best growth under moderate salt stress. Jerusalem artichoke avoided salt damage by not extending roots to deep soil, so most of the root system of NY-1 mainly grew in the soil layer 75-175 mm deep. Hence, the root distribution pattern reflected the adaptive mechanisms of Jerusalem artichoke under salinity stress. Root channels represent a complex interface that is not only the living space of plant roots, microbes and soil animals, but also plays an important role in dynamics of water, nutrients, gas, heat, and other factors in soil (Gupta et al., 2008; Gupta, Naushad \& Baker, 2015; Wang, Zhang, Yang, Li \& Liu, 2018). The root channels of Jerusalem artichoke improved the physical structure of saline soil and provided basic conditions for the optimization of the soil micro-ecological environment.

\subsection{Rhizosphere secretions}

Rhizosphere secretions are important in the organic and inorganic matter cycling and energy flow between plants and the environment. Organisms such as plants and microbes adapt to their habitats and influence their surroundings by releasing various high- and low-molecular-weight metabolites and ions into the environment, with up to $50 \%$ of photosynthetic products potentially released as rhizosphere secretions (Zhang, Li \& Wang, 2007; van Dam \& Bouwmeester, 2016). High-molecular-weight metabolites in secretions (carbohydrates, hydrocarbons, etc.) may adhere strongly to soil particles. Such adhesion promotes the formation of soil aggregates, changes the soil structure, and improves the physical and chemical properties of the soil. In addition, organic acid anions could increase availability of nutrients in the rhizosphere by their chelating capacity (Killham, 1994). The acid/ester compounds detected in the present study were mainly dibutyl phthalate (DBP), which is a potential allelopathic substance. Low concentration of DBP increased the content of chlorophyll in leaves and the activities of urease and catalase in soil, and enhanced the plant capacity to resist stress, but high concentration had the opposite effect (Keire et al., 2001; Deng et al., 2017).

Different secretions would have differential effects on the surroundings, including an effect on the formation of a specific microbial community in the rhizosphere soil (Sturz \& Christie, 2003), and influencing not only the abundance and type of microorganisms, but also growth and metabolism as well as community composition of microorganisms (Haldar \& Sengupta, 2015; Ankati \& Podile, 2019; Vives-Peri, de Ollas, Gómez-Cadenas \& Perez-Clemente, 2020). Obviously, the rhizosphere microbial community structure is the result of a series of complex interactions and feedbacks between the roots, the microbes and the physical and chemical environment of the soil. There are numerous studies demonstrating that plant development influences the composition and function of the soil microbiome (e.g. Rodriguez, Muñera \& Peñuela, 2016; Zhalnina et al., 2018; Shao et al., 2020; Xu et al., 2020). The microorganisms that tend to gather near roots, such asGeobacter, Cupriavidus, Halorhodospira, Marichromatium, Rhodobacter, Rhodovulum, Rubrivivax, Sideroxydans ,Pseudacidovorax, Sinorhizobium, Leptothrix and Methylocystis, etc. in the present study (Figs $3,4)$ influence the rhizosphere environment and may decompose and transform rhizosphere secretions.

\subsection{Soil microbes}

Microorganisms are the driving force for nutrient conversion and cycling, having the characteristics of large biomass, complex community composition, diverse metabolic functions, and complex interactive relationships (Bardgett \& van der Putten, 2014). They can mediate important metabolic processes in the carbon and nitrogen cycles (Brussaard, de Ruiter \& Brown, 2007). Climate change caused by greenhouse gas emissions has long been an important global issue. Therefore, biological mitigation of $\mathrm{CO}_{2}$ emissions has attracted the attention of many researchers (Mahinpey, Asghari \& Mirjafari, 2011; Farrelly, Everard, Fagan \& McDonnell, 2013). Aboveground plant parts provide organic carbon sources for roots and soil organisms, thus influencing strongly the underground system. In particular, rhizosphere secretions provide carbon sources and energy for the growth of microorganisms (Stephan Shockey, Moe \& Dorn, 2002; van der Wielen, 2006; Selesi, Pattis, Schmid, Kandeler \& Hartmann, 2007).

We found in our previous research that Jerusalem artichoke played a significant role in increasing soil microbial populations. We reported greater relative abundance of p_Proteobacteria, p_Bacteroidetes and p_- 
Cyanobacteria in the bulk than rhizosphere soil, whereas p_Acidobacteria, p_Chloroflexi and p_Nitrospirae abundance was greater in the rhizosphere than bulk soil (Shao et al. 2019). Here, almost all autotrophic microorganisms and nitrogen-fixing microorganisms belonged to p_Proteobacteria, and its relative abundance in bulk soil was slightly lower than that in rhizosphere soil.

Among $c b b L$-containing autotrophic bacteria, the relative abundance of $c_{-}$Ga mmaproteobacteria exceeded $65 \%$ in the bulk and rhizosphere soils, including the five dominant genera: g_Halorhodospira, g_Marichromatium, g_Thioalkalivibrio, g_Alkalilimnicola, and g_Ectothiorhodospira, all of which grow in oceans or high-salt environments where the $\mathrm{pH}$ is neutral to extremely alkaline (Sorokin, Muntyan, Panteleeva \& Muyzer, 2012). There were also three dominant genera: g_Thiobacillus , g_Cupriavidus and $g_{-}$Hydrogenophaga, all belonging to $c_{-}$Betaproteobacteria .

Almost all of the unique $c b b M$-containing autotrophic bacteria in the rhizosphere soils belonged to $c_{-}-$ Betaproteobacteria, c_Alphaproteobacteria and $c_{-}$Actinobacteria, and the five dominant genera were $g_{-}-$ Halothiobacillus, g_Sideroxydans, g_Rhodopseudomonas, g_Thiobacillus, and g_Sulfuritalea . The previous research data of our team demonstrated that the content of soil organic carbon $(12.8 \pm 0.79 \mathrm{~g} / \mathrm{kg})$ and total nitrogen of the Jerusalem artichoke planting area $(0.96 \pm 0.21 \mathrm{~g} / \mathrm{kg})$ in this experimental area were significantly higher than those of the bare control soil $(5.6 \pm 0.89 \mathrm{~g} \mathrm{C} / \mathrm{kg}$ and $0.40 \pm 0.04 \mathrm{~g} \mathrm{~N} / \mathrm{kg})(\mathrm{Li}$ et al., 2018). In the study presented here, the community diversity of $c b b M$-containing autotrophic bacteria and nitrogen-fixing bacteria containing nifH showed the order of rhizosphere soil $>$ bulk soil, which indicated that Jerusalem artichoke could enhance soil fixation of carbon and nitrogen by changing the community composition of soil microorganisms.

Soil environments with low $\mathrm{CO}_{2}$ concentration are beneficial to the growth of autotrophic bacteria containing the $c b b L$ gene, whereas the autotrophic bacteria with the $c b b M$ gene are relatively abundant at low oxygen and high $\mathrm{CO}_{2}$ concentrations (Videmsek et al., 2009), which was confirmed in the present study. Sideroxydans is a Fe-oxidizing bacterium. Thiobacillus and Sulfuritalea are ammonia-oxidizing bacteria, and both can also provide the available sulfate-sulfur plants can take up. In addition, Sulfuritalea also functions in the denitrification process. Some species of Hydrogenophaga also have anaerobic nitrate respiration and are denitrifiers (Vandamme \& Coenye, 2004; Jazaeri, Akhgar, Sarcheshmehpour \& Mohammad, 2016). Four dominant genera containing nifH were: g_Desulfuromonas, g_Geobacter, g_Geoalkalibacter, and g_Anaeromyxobacter, allbelonging to c_Deltaproteobacteria (Holmes, Nevin \& Lovley, 2004; Zavarzina et al., 2006). Deltaproteobacteria exhibit considerable anaerobic physiological diversity, including sulfate reduction, iron reduction ( $g_{-}$Geobacter ), fermentation, and dehalogenation (Nevin, Holmes, Woodard, Covalla \& Lovley, 2007). Moreover, rhizobia (g_Rhizobium, g_Bradyrhizobium, g_Sinorhizobium, and g_Azorhizobium) are symbiotic nitrogen-fixers, and responsible for the major share of global fixation of atmospheric nitrogen, and require low concentration of oxygen (Viprey, Rosenthal, Broughton \& Perret, 2000; Lodwig et al., 2003). In the present study, the abundance of Gammaproteobacteria andDeltaproteobacteria at given soil salinity was higher in the bulk than rhizosphere soil. In contrast, the relative abundance of Betaproteobacteria and Alphaproteobacteria was significantly higher in the rhizosphere than bulk soil, and the abundance was higher in low-salinity than high-salinity soils (Table 1). Most Betaproteobacteria are resistant to low $\mathrm{pH}$ and high temperature, and prefer low-oxygen conditions. BothBetaproteobacteria and Gammaproteobacteria include nitrogen-fixing rhizobia (Moulin, Munive, Dreyfus \& Boivin-Masson, 2001; Shiraishi, Matsushita \& Hougetsu, 2010; Klann, McHenry, Montelongo \& Goffredi, 2016).

We also found other functional microorganisms such as aerobic methane oxidizing bacteria ( $g_{-}$Methylibium, g_Methylobacter, g_Methylobacterium, etc. ), desulfurization bacteria ( $g_{-}$Desulfarculus, $g_{-}$Desulfatibacillum, g_Desulfitobacterium, etc. ), nitrifying bacteria (g_Nitrobacter, g_Nitrosospira, g_Nitrospira, etc. ), sulfur-oxidizing bacteria (g_Sulfuricurvum, g_Ectothiorhodospira, g_Halothiobacillus, etc. ), and photosynthetic bacteria (g_Rhodobacter, g_Rhodococcus, g_Rhodospirillum, etc. ). This indicated that some autotrophic and nitrogen-fixing microorganisms are not involved only in the carbon and nitrogen cycle, but also may participate in the biogeochemical cycles of other elements, thus playing a role in material cycling and energy flow in the micro-ecological environments in saline soils. Microbial communities with different functionalities 
jointly regulate and drive the various processes in the element cycling, and play an irreplaceable role in responding to global climate change and maintaining the function and stability of the ecosystems (Bardgett, Freeman \& Ostle, 2008; Zhou et al. 2012; Madigan, Bender, Buckley, Sattley \& Stahl, 2019).

\section{Conclusions}

In this study, the modification effect of in situ Jerusalem artichoke cultivation on the micro-ecological rhizosphere environment in the saline-alkali soils along the southeast coast of China was elucidated from a microbial perspective. The root system of Jerusalem artichoke was distributed mainly in the soil layer 75-175 mm, avoiding salt damage (high salinity in the top and the deeper layers). The root channels of Jerusalem artichoke improved not only the physical structure of saline soil, but also provided basic conditions for optimizing the soil micro-ecological environment. Rhizosphere exudates (such as carbohydrates, hydrocarbons, acids, etc.), produced by Jerusalem artichoke and soil microbial community, could improve the habitat of saline soil. The community diversity and richness of the autotrophic bacteria and nitrogen-fixing bacteria were greater in the rhizosphere than bulk soils. Many of identified microorganisms participate not only in the carbon and nitrogen cycles, but also in the biogeochemical cycles of other elements, promoting material cycling and energy flow in the micro-ecological environments in saline soils. These findings provided a scientific basis for understanding the biotransformation of carbon and nitrogen in saline soil and the positive effects of Jerusalem artichoke on the micro-ecological rhizosphere environment in saline soil.

\section{Declaration of competing interest}

No conflict of interest exists.

\section{Authors' contributions}

S.T.Y., L.X.H. and L.M.Q. conceived the ideas and designed methodology; S.T.Y., L.X.H. and G.X.M. collected the data; S.T.Y. analysed the data; S.T.Y. and Z.R. led the writing of the manuscript. All authors contributed critically to the drafts and gave final approval for publication.

\section{Acknowledgements}

This work was financially supported by the Jiangsu Agricultural Science and Technology Independent Innovation Fund Project [CX(18)2013], Forestry Science and Technology Innovation and Extension Project in Jiangsu Province (No. LYKJ[2019]07), the Natural Science Foundation of Jiangsu Province of China (BK20181165), the 5th Scientific Research Project of "333 High-level Talents Training Project" of Jiangsu Province (BRA2020128), the National Key Research and Development Program of China (2016YFC0501207), the National Key Project of Scientific and Technical Supporting Programs funded by the Ministry of Science \& Technology of Jiangsu Province (BE2018387 and BE2017310-2), and the Fundamental Research Funds for the Central Universities (KYYJ201902, KYZ201623, YZ2016-1 and KYYJ201703). There are no competing financial interests associated with the publication of this article.

\section{References}

Abogadallah, G. M. (2010). Insights into the significance of antioxidative defense under salt stress. Plant Signaling and Behavior, 5(4), 369-374. https://doi.org/10.4161/psb.5.4.10873.

Alfreider, A., Vogt, C., Hoffmann, D., \& Babel, W. (2003). Diversity of ribulose-1,5-bisphosphate carboxylase/oxygenase large-subunit genes from groundwater and aquifer microorganisms. Microbial Ecology, 45 , 317-328. https://doi.org/10.1007/s00248-003-2004-9.

Ankati, S., \& Podile, A. R. (2019). Metabolites in the rhizosphere exudates of groundnut change during interaction with plant growth promoting rhizobacteria in a strain-specific manner. Journal of plant physiology, 243, 153057. https://doi.org/10.1016/j.jplph.2019.153057.

Bardgett, R. D., Freeman, C., \& Ostle, N. J. (2008). Microbial contributions to climate change through carbon cycle feedbacks.ISME Journal, 2(8), 805-814. https://doi.org/10.1038/ismej.2008.58. 
Bardgett, R. D., \& van der Putten, W. (2014). Belowground biodiversity and ecosystem functioning. Nature, 515(7528), 505-511. https://doi.org/10.1038/nature13855.

Brussaard, L., de Ruiter, P. C., \& Brown, G. G. (2007). Soil biodiversity for agricultural sustainability. Agriculture, Ecosystems \& Environment, 121(3), 233-244. https://doi.org/10.1016/j.agee.2006.12.013.

Carvalhais, L. C., Dennis, P. G., Badri, D. V., Kidd, B. N., Vivanco, J. M., \& Schenk, P. M. (2015). Linking jasmonic acid signaling, root exudates, and rhizosphere microbiomes. Molecular Plant-Microbe Interactions, 28(9), 1049-58. https://doi.org/10.1094/MPMI-01-15-0016-R.

Deng, J. J., Zhang, Y. L., Hu, J. W., Jiao, J. G., Hu, F., Li, H. X., \& Zhang, S. X. (2017). Autotoxicity of phthalate esters in tobacco root exudates: effects on seed germination and seedling growth.Pedosphere, 27(6), 1073-82. https://doi.org/10.1016/S1002-0160(17)60374-6.

Diacono, M., \& Montemurro, F. (2010). Long-term effects of organic amendments on soil fertility. A review. Agronomy for Sustainable Development, 30, 401-422. https://doi.org/10.1051/agro/2009040.

Farrelly, D. J., Everard, C. D., Fagan, C. C., \& McDonnell, K. P. (2013). Carbon sequestration and the role of biological carbon mitigation: a review. Renewable and Sustainable Energy Reviews, 21, 712-727. https://doi.org/10.1016/j.rser.2012.12.038.

Guillot, G., \& Rousset, F. (2013). Dismantling the Mantel tests. Methods in Ecology and Evolution, 4, 336344. https://doi.org/10.1111/2041-210x.12018.

Gupta, R. K., Abrol, I. P., Finkl, C. W., Kirkham, M. B., Arbestain, M. C., Macías, F., Chesworth, W., Germida, J. J., Loeppert, R. H., Cook, M. G., Schwab, G. O., Konstankiewicz, K., Pytka, J., Oertli, J. J., Singer, A., Edmonds, W. J., Feng, Y. C., Feldman, S. B., Shang, C., Zelazny, L. W., Ford, P. W., \& Clothier, B. E. (2008). Soil Pores. In: W. Chesworth (Eds.), Encyclopedia of soil science. Encyclopedia of earth sciences series. Dordrecht, Netherlands: Springer. https://doi.org/10.1007/978-1-4020-3995-9548.

Gupta, R. S., Naushad, S., \& Baker, S. (2015). Phylogenomic analyses and molecular signatures for the class Halobacteria and its two major clades: a proposal for division of the class Halobacteria into an emended order Halobacteriales and two new orders, Haloferacales ord. nov. and Natrialbales ord. nov., containing the novel families Haloferacaceae fam. nov. and Natrialbaceae fam. nov. International Journal of Systematic and Evolutionary Microbiology, 65(Pt 3), 1050-69. https://doi.org/10.1099/ijs.0.070136-0.

Haldar, S., \& Sengupta, S. (2015). Plant-microbe cross-talk in the rhizosphere: insight and biotechnological potential. The Open Microbiology Journal, 9, 1-7. https://doi.org/10.2174/1874285801509010001.

Hartle, R. T., Fernandez, G. C. J., \& Nowak, R. S. (2006). Horizontal and vertical zones of influence for root systems of four Mojave Desert shrubs. Journal of Arid Environments, 64(4), 586-603. https://doi.org/10.1016/j.jaridenv.2005.06.021.

Holmes, D. E., Nevin, K. P., \& Lovley, D. R. (2004). Comparison of $16 S$ rRNA, nifD, recA, gyrB, rpoB and fusAgenes within the family Geobacteraceae fam. nov.International Journal of Systematic Bacteriology, 54(Pt5), 1591-9. https://doi.org/10.1099/ijs.0.02958-0.

Jazaeri, M., Akhgar, A., Sarcheshmehpour, M., \& Mohammad, A. H. (2016). Bioresource efficacy of phosphate rock, sulfur and Thiobacillusinoculum in improving soil phosphorus availability. Communications in Soil Science and Plant Analysis, 47(11), 1441-50. https://doi.org/10.1080/00103624. 2016.1179750.

Jiang, S. Q., Yu, Y. N., Gao, R.W., Wang, H., Zhang, J., Li, R., Long, X. H., Shen, Q. R., Chen, W., \& Cai, F. (2019). High-throughput absolute quantification sequencing reveals the effect of different fertilizer applications on bacterial community in a tomato cultivated coastal saline soil. Science of the Total Environment, 687(15),601-9. https://doi.org/10.1016/j.scitotenv.2019.06.105.

Keire, D. A., Anton, P., Faull, K. F., Ruth, E., Walsh, J. H., Chew, P., Quisimorol, D., Territo, M., \& Reeve, J. R. (2001). Diethyl phthalata, a chemotactic factor secreted by Helicobacter pylori. Journal of Biological 
Chemistry, 276(52), 48847-53. https://doi.org/10.1074/jbc.M109811200.

Killham, K. (1994). Soil ecology. Cambridge University Press, Cambridge.

Klann, J., McHenry, A., Montelongo, C., \& Goffredi, S. K. (2016). Decomposition of plant-sourced carbon compounds by heterotrophicbetaproteobacteria isolated from a tropical Costa Rican bromeliad. Microbiology Open, 5(3), 479-89. https://doi.org/10.1002/mbo3.344.

Kraemer, S. A., Ramachandran, A., Colatriano, D., Lovejoy, C., \& Walsh, D. A. (2020). Diversity and biogeography of SAR11 bacteria from the Arctic Ocean. ISME Journal, 14(12), 79-90. https://doi.org/10.1038/s41396-019-0499-4.

Kuffner, M., Hai, B., Rattei, T., Melodelima, C., Schloter, M., Zechmeister-Boltenstern, S., Jandl, R., Schindlbacher, A., \& Sessitsch, A. (2012). Effects of season and experimental warming on the bacterial community in a temperate mountain forest soil assessed by $16 \mathrm{~S}$ rRNA gene pyrosequencing. FEMS Microbiology Ecology, 82(3), 551-562. https://doi.org/10.1111/j.1574-6941.2012.01420.x.

Lauber, C. L., Zhou, N., Gordon, J. I., Knight, R., \& Fierer, N. (2010). Effect of storage conditions on the assessment of bacterial community structure in soil and human-associated samples. FEMS Microbiology Letters, 307, 80-86. https://doi.org/10.1111/j.1574-6968.2010.01965.x.

Li, N., Shao, T., Zhu, T. S., Long, X. H., Gao, X. M., Liu, Z. P., Shao, H. B., \& Rengel, Z. (2018). Vegetation succession influences soil carbon sequestration in coastal alkali-saline soils in southeast China.Scientific Reports, 8, 9728. https://doi.org/10.1038/s41598-018-28054-0.

Liu, S. L., Hou, X. Y., Yang, M., Cheng, F. Y., Coxixo, A., Wu, X., \& Zhang, Y. Q. (2018). Factors driving the relationships between vegetation and soil properties in the Yellow River Delta, China.Catena, 165, 279-85. https://doi.org/10.1016/j.catena.2018.02.004.

Liu, W. X., Hou, J. Y., Wang, Q. L., Yang, H. J., Luo, Y. M., \& Christie, P. (2015). Collection and analysis of root exudates ofFestuca arundinacea L. and their role in facilitating the phytoremediation of petroleumcontaminated soil. Plant and Soil, 389(1-2), 109-119. https://doi.org/10.1007/s11104-014-2345-9.

Lodwig, E. M., Hosie, A. H. F., Bourdes, A., Findlay, K., Allaway, D., Karunakaran, R., Downie, J.A., \& Poole, P. S. (2003). Amino-acid cycling drives nitrogen fixation in the legume-Rhizobium symbiosis.Nature, 422, 722-6. https://doi.org/10.1038/nature01527.

Long, X. H., Huang, Z. R., Huang, Y. L., Kang, Y. L., Zhang, J., \& Liu, Z. H. (2010). Response of two Jerusalem artichoke (Helianthus tuberosus ) cultivars differing in tolerance to salt treatment.Pedosphere, 20(4), 515-524. https://doi.org/10.1016/S1002-0160(10)60041-0.

Madigan, M. T., Bender, K. S., Buckley, D. H., Sattley, W. M., \& Stahl, D. A. (2019). Unit 5: Microbial Ecology and Environmental Microbiology. Brock Biology of Microorganisms (15th ed.). San Francisco: Pearson Education.

Mahinpey, N., Asghari, K., \& Mirjafari, P. (2011). Biological sequestration of carbon dioxide in geological formations. Chemical Engineering Research and Design, 89(9), 1873-78. https://doi.org/10.1016/j.cherd.2010.10.016.

Mao, W. B., Kang, S. Z., Wan, Y. S., Sun, Y. X., Li, X. H., \& Wang, Y. F. (2016). Yellow River sediment as a soil amendment for amelioration of saline land in the Yellow River delta. Land Degradation 83 Development, 27(6), 1595-1606. https://doi.org/10.1002/ldr.2323.

Marschner, H. (1995). Mineral nutrition of higher plants (2nd ed.). London: Academic Press, pp. 889. https://doi.org/10.1016/B978-0-12-473542-2.X5000-7.

Moulin, L., Munive, A., Dreyfus, B., \& Boivin-Masson, C. (2001). Nodulation of legumes by members of the $\beta$-subclass of proteobacteria.Nature, 411, 948-950. https://doi.org/10.1038/35082070. 
Nevin, K. P., Holmes, D. E., Woodard, T. L., Covalla, S. F., \& Lovley, D. R. (2007). Reclassification of Trichlorobacter thiogenes asGeobacter thiogenes comb. nov. International Journal of Systematic and Evolutionary Microbiology, 57(Pt3), 463-6. https://doi.org/10.1099/ijs.0.63408-0.

Oksanen, J., Blanchet, F. G., Friendly, M., Kindt, R., Legendre, P., McGlinn, D., Minchin, P. R., O'Hara, R. B., Simpson, G. L., Solymos, P., Stevens, M. H. H., Szoecs, E., \& Wagner, H. (2019, September 01). https://lib.ugent.be/CRAN/web/packages/vegan/index.html. Vegan 2.5-6: Community Ecology Package.

Rodriguez, N. J. P., Muñera, L. M., \& Peñuela, G. A. (2016). Root exudates and plant secondary metabolites of different plants enhance polychlorinated biphenyl degradation by rhizobacteria.Bioremediation Journal, 20(2), 108. https://doi.org/10.1080/10889868.2015.1124065.

San, J. M. F., Caniego, F. J., \& García, G. C. (2017). Lacunarity of soil macropore space arrangement of CT images: Effect of soil management and depth. Geoderma, 287, 80-89. https://doi.org/10.1016/j.geoderma.2016.09.007.

Sedgwick, P. (2014). Spearman's rank correlation coefficient. BMJ Journals, 349(nov28 1), g7528. https://doi.org/10.1136/bmj.g7327.

Selesi, D., Pattis, I., Schmid, M., Kandeler, E., \& Hartmann, A. (2007). Quantification of bacterial Rubis$C O$ genes in soils by $c b b L$ targeted real-time PCR. Journal of Microbiological Methods, 69, 497-503. https://doi.org/10.1016/j.mimet.2007.03.002.

Shao, T. Y., Gu, X. Y., Zhu, T. S., Pan, X. T., Zhu, Y., Long, X. H., Shao, H. B., Liu, M. Q., \& Rengel, Z. (2019). Industrial crop Jerusalem artichoke restored coastal saline soil quality by reducing salt and increasing diversity of bacterial community. Applied Soil Ecology, 138, 195-206. https://doi.org/10.1016/j.apsoil.2019.03.003.

Shao, T.Y., Zhao, J.J., Liu, A.H., Long, X.H., Shao, H.B., Liu, M.Q. \& Rengel, Z. (2020). Effects of soil physicochemical properties on microbial communities in different ecological niches in coastal area.Applied Soil Ecology, 150, 103486. https://doi.org/10.1016/j.apsoil.2019.103486

Shi, S. J., Richardson, A. E., Callaghan, M. O., Deangelis, K. M., Jones, E. E., Stewart, A., Firestone, M. K., \& Condron, L. M. (2011). Effects of selected root exudate components on soil bacterial communities. FEMS Microbiology Ecology, 77(3), 600-610. https://doi.org/10.1111/j.1574-6941.2011.01150.x

Shiraishi, A., Matsushita, N., \& Hougetsu, T. (2010). Nodulation in black locust by the Gammaproteobacteria Pseudomonas sp. and theBetaproteobacteria Burkholderia sp. Systematic and Applied Microbiology, 33(5), 269-274. https://doi.org/10.1016/j.syapm.2010.04.005.

Shrivastava, P., \& Kumar, R. (2015). Soil salinity: a serious environmental issue and plant growth promoting bacteria as one of the tools for its alleviation. Saudi Journal of Biological Sciences, 22(2), 123-131. doi:10.1016/j.sjbs.2014.12.001.

Sorokin, D. Y., Muntyan, M. S., Panteleeva, A. N., \& Muyzer, G. (2012). Thioalkalivibrio sulfidiphilus sp. nov., a haloalkaliphilic, sulfur-oxidizing Gammaproteobacterium from alkaline habitats.International Journal of Systematic and Evolutionary Microbiology, 62(Pt8), 1884-9. https://doi.org/10.1099/ijs.0.034504-0.

Stephan, D. J., Shockey, R. E., Moe, T. A., \& Dorn, R. (2002). Carbon dioxide sequestering using microalgal systems. Grand Forks: University of North Dakota. https://doi.org/10.2172/882000.

Sturz, A. V., \& Christie, B. R. (2003). Beneficial microbial allelopathies in the root zone: The management of soil quality and plant disease with rhizobacteria. Soil and Tillage Research, 72(2),107-23. https://doi.org/10.1016/S0167-1987(03)00082-5.

Tatangelo, V., Franzetti, A., Gandolfi, I., Bestetti, G., \& Ambrosini, R. (2014). Effect of preservation method on the assessment of bacterial community structure in soil and water samples. FEMS Microbiology Letters, 356, 32-38. https://doi.org/10.1111/1574-6968.12475. 
Tourova, T. P., Kovaleva, O. L., Sorokin, D. Y., \& Muyzer, G. (2010). Ribulose-1,5-bisphosphate carboxylase/oxygenase genes as a functional marker for chemolithoautotrophic halophilic sulfur-oxidizing bacteria in hypersaline habitats. Microbiology, 156(Pt7), 2016-25. https://doi.org/10.1099/mic.0.034603-0.

van Dam, N. M., \& Bouwmeester, H. J. (2016). Metabolomics in the rhizosphere: tapping into belowground chemical communication. Trends in Plant Science, 21(3), 256-265. https://doi.org/10.1016/j.tplants.2016.01.008.

van der Wielen, P. W. (2006). Diversity of ribulose-1,5-bisphosphate carboxylase/oxygenase large-subunit genes in the $\mathrm{MgCl}_{2}$-dominated deep hypersaline anoxic basin discovery.FEMS Microbiology Letters, 259(2), 326-331. https://doi.org/10.1111/j.1574-6968.2006.00284.x.

Vandamme, P., \& Coenye, T. (2004). Taxonomy of the genusCupriavidus : a tale of lost and found. International Journal of Systematic and Evolutionary Microbiology, 54(Pt6), 2285-9. https://doi.org/10.1099/00207713-39-3-319.

Videmsek, U., Hagn, A., Suhadolc, M., Radl, V., Knicker, H., Schloter, M., \& Vodnik, D. (2009). Abundance and diversity of $\mathrm{CO}_{2}$-fixing bacteria in grassland soils close to natural carbon dioxide springs. Microbial Ecology, 58(1), 1-9. https://doi.org/10.1007/s00248-008-9442-3.

Viprey, V., Rosenthal, A., Broughton, W. J., \& Perret, X. (2000). Genetic snapshots of the rhizobium species NGR234 genome.Genome Biology, 1(6), research0014.1-17. https://doi.org/10.1186/gb-2000-1-6research0014.

Vives-Peris, V., de Ollas, V. C., Gómez-Cadenas, A., \& Perez-Clemente, R. M. (2020). Root exudates: from plant to rhizosphere and beyond.Plant Cell Reports, 39(3), 3-17. https://doi.org/10.1007/s00299-019-024475 .

Wang, B., Zhang, G. H., Yang, Y. F., Li, P. P., \& Liu, J. X. (2018). Response of soil detachment capacity to plant root and soil properties in typical grasslands on the Loess Plateau. Agriculture, Ecosystems $\mathcal{E}^{3}$ Environment, 266, 68-75. https://doi.org/10.1016/j.agee.2018.07.016

Xia, J. B., Ren, J. Y., Zhang, S. Y., Wang, Y. H., \& Fang, Y. (2019). Forest and grass composite patterns improve the soil quality in the coastal saline-alkali land of the Yellow River Delta, China.Geoderma, 349, 25-35. https://doi.org/10.1016/j.geoderma.2019.04.032.

Xu, Z. K., Shao, T. Y., Lv, Z. X., Yue, Y., Liu, A. H., Long, X. H., Zhou, Z. S., Gao, X. M., \& Rengel, Z. (2020). The mechanisms of improving coastal saline soils by planting rice. Science of the Total Environment, 703, 135529. https://doi.org/10.1016/j.scitotenv.2019.135529.

Yu, P.J., Liu, S.W., Yang, H.T., Fan, G.H., \& Zhou, D.W., 2018. Short-term land use conversions influence the profile distribution of soil salinity and sodicity in northeastern. Ecological Indicators, 88, 79-87. https://doi.org/10.1016/j.ecolind.2018.01.017.

Yue, Y., Shao, T. Y., Long, X. H., He, T. F., Gao, X. M., Zhou, Z. S., Liu, Z. P., \& Rengel, Z. (2020). Microbiome structure and function in rhizosphere of Jerusalem artichoke grown in saline land. Science of the Total Environment, 724, 138259. https://doi.org/10.1016/j.scitotenv.2020.138259.

Zavarzina, D. G., Kolganova, T. V., Boulygina, E. S., Kostrikina, N. A., Turova, T. P., \& Zavarzin, G. A. (2006). Geoalkalibacter ferrihydriticus gen. nov. sp. nov., the first alkaliphilic representative of the family Geobacteraceae, isolated from a soda lake. Microbiology, 75(6), 775-85. https://doi.org/10.1134/S0026261706060099.

Zhalnina, K., Louie, K. B., Hao, Z., Mansoori, N., da Rocha, U. N., Shi, S. J., Cho, H. J., Karaoz, U., Loqué, D., Bowen, B. P., Firestone, M. K., Northen, T. R., \& Brodie, E. L. (2018). Dynamic root exudate chemistry and microbial substrate preferences drive patterns in rhizosphere microbial community assembly. Nature Microbiology, 3,470-480. https://doi.org/10.1038/s41564-018-0129-3 
Zhang, X. Z., Li, T. X., \& Wang, Y. D. (2007). Relationship between growth environment and root exudates of plants: A review. Chinese Journal of Soil Science, 38(4), 785-9. (Chinese) https://doi.org/10.3969/j.issn.1674-5906.2000.01.017.

Zhou, J. Z., Xue, K., Xie, J. P., Deng, Y., Wu, L. Y., Cheng, X. L., Fei, S. F., Deng, S. P., He, Z. L., Van Nostrand, J. D., Luo, Y. Q. (2012). Microbial mediation of carbon-cycle feedbacks to climate warming. Nature Climate Change, 2, 106-110. https://doi.org/10.1038/nclimate1331.

\section{Figures and tables}

Figure 1 An analysis of the variation in root channel area with soil depth in different types of soil.

Note: H- high salinity; M- moderate salinity; L- low salinity; UP- soil under the plants (a circular area with a radius of $13 \mathrm{~cm}$ centered on the plant stem); IR- inter-row soil. The data are means $(\mathrm{n}=5)$. (A) The variation trend of channel area in different soils with increasing soil depth; (B) Different lower case letters denote significant differences among different soil sample types at a given soil depth ( $\mathrm{p}[?] 0.05)$. The ratios of the root channel area in the 0-200 $\mathrm{mm}$ soil layer and the 200-400 $\mathrm{mm}$ soil layer for seven different types of soil were indicated above the lower case letters.

Figure 2 Rhizosphere secretions in different soil samples.

Note: H- high salinity; M- moderate salinity; L- low salinity; R- rhizosphere soil; NR- bulk soil; CK- highly saline unplanted control soil. The data are means $(n=5)$. (A) Stacked histograms of the relative proportions of various compounds in different soil samples. The percentages greater than $1 \%$ are shown only. (B), (C), (D) Histograms of relative proportions and significant differences in specific rhizosphere secretions in different soil samples. Different lower case letters denote significant differences among different soil sample types for a given secretion (p [?]0.05).

Figure 3 Diversity of soil autotrophic bacteria based on $c b b L$ and $c b b M$ sequencing.

Note: H- high salinity; M- moderate salinity; L- low salinity; R- rhizosphere soil; NR- bulk soil; CKhighly saline unplanted control soil. The data are means $(n=5)$. (A) and (C) Alpha diversity indices of autotrophic bacteria containing $c b b L(\mathrm{~A})$ and $c b b M(\mathrm{C})$. (B) and (D) Doughnuts of the abundance of genera of autotrophic bacteria containing $c b b L$ (B) and $c b b M$ (D). (E) and (F) Stacked histograms of the relative proportions of different genera of autotrophic bacteria containing $c b b L(\mathrm{E})$ and $c b b M(\mathrm{~F}) .(\mathrm{G})$ and $(\mathrm{H})$ LDA Effect Size (LEfSe) of autotrophic bacteria containing $c b b L(\mathrm{G})$ and $c b b M(\mathrm{H})$.

Figure 4 Diversity of soil nitrogen-fixing bacteria.

Note: H- high salinity; M- moderate salinity; L- low salinity; R- rhizosphere soil; NR- bulk soil; CK- highly saline unplanted control soil. The data are means $(n=5)$. (A) Alpha diversity index ofnifH -containing nitrogen-fixing bacteria; (B) Hierarchical cluster analysis among samples; (C) Stacked histograms of the percentage of different genera of nifH -containing nitrogen-fixing bacteria in different soil samples; (D) LDA Effect Size (LEfSe) of nifH .

Figure 5 Correlations among soil physical and chemical properties, rhizosphere secretions and bacterial abundance.

table 1 Abundance and characteristics of important microorganisms 


\begin{tabular}{|c|c|c|c|}
\hline Types of microbes & $\begin{array}{l}\text { In CK and NR (relative } \\
\text { abundance: } N R>R \text { ) }\end{array}$ & $\begin{array}{l}\text { In R (relative abundance: } \\
\mathrm{R}>\text { NR) }\end{array}$ & General characteristics \\
\hline $\begin{array}{l}\text { Autotrophic bacteria } \\
\text { containing } c b b L\end{array}$ & $\begin{array}{l}\text { Gammaproteobacteria } \\
\text { was the main class. The } \\
\text { correlation between } \\
\text { relative abundance and } \\
\text { soil salinity was positive } \\
\text { and significant. }\end{array}$ & $\begin{array}{l}\text { Gammaproteobacteria } \\
\text { was the main class. In } \\
\text { moderate and low salinity } \\
\text { soils, Betaproteobacteria } \\
\text { and Alphaproteobacteria } \\
\text { also had large relative } \\
\text { abundance. }\end{array}$ & $\begin{array}{l}\text { Community diversity and } \\
\text { richness: NR > R. } \\
\text { Relationship between } \\
\text { relative abundance and } \\
\text { pH: negative correlation } \\
(\mathrm{r}<-0.6) \text {. Soil } \\
\text { environments with } \\
\text { sufficient oxygen and low } \\
\mathrm{CO}_{2} \text { concentration were } \\
\text { conducive to survival. }\end{array}$ \\
\hline $\begin{array}{l}\text { Autotrophic bacteria } \\
\text { containing } c b b M\end{array}$ & $\begin{array}{l}\text { Gammaproteobacteria } \\
\text { and Alphaproteobacteria } \\
\text { were the main classes. } \\
\text { Relationship between } \\
\text { relative abundance of } \\
\text { Betaproteobacteria and } \\
\text { salinity: significant } \\
\text { negative correlation. }\end{array}$ & $\begin{array}{l}\text { Betaproteobacteria and } \\
\text { Alphaproteobacteria were } \\
\text { the main classes. } \\
\text { Relationship between } \\
\text { relative abundance of } \\
\text { Gammaproteobacteria } \\
\text { and salinity: significant } \\
\text { negative correlation. }\end{array}$ & $\begin{array}{l}\text { Community diversity and } \\
\text { richness: } \mathrm{R}>\mathrm{NR} \text {. } \\
\text { Relationship between } \\
\text { relative abundance and } \\
\mathrm{pH} \text { : negative correlation } \\
(\mathrm{r}<-0.5) \text {. Soil } \\
\text { environments with low } \\
\text { oxygen and high } \mathrm{CO}_{2} \\
\text { concentration were } \\
\text { conducive to survival. }\end{array}$ \\
\hline $\begin{array}{l}\text { Nitrogen-fixing bacteria } \\
\text { containing nifH }\end{array}$ & $\begin{array}{l}\text { Gammaproteobacteria } \\
\text { and Deltaproteobacteria } \\
\text { were the main classes. } \\
\text { Relationship between } \\
\text { relative abundance and } \\
\text { salinity: significant } \\
\text { positive correlation. }\end{array}$ & $\begin{array}{l}\text { Betaproteobacteria and } \\
\text { Alphaproteobacteria were } \\
\text { the main classes. } \\
\text { Relationship between } \\
\text { relative abundance and } \\
\text { salinity: significant } \\
\text { negative correlation. }\end{array}$ & $\begin{array}{l}\text { Community diversity and } \\
\text { richness: } \mathrm{R}>\mathrm{NR} \text {. } \\
\text { Relationship between } \\
\text { relative abundance and } \\
\mathrm{pH} \text { : negative correlation } \\
(\mathrm{r}<-0.5) \text {. Soil } \\
\text { environments with low } \\
\text { oxygen were conducive to } \\
\text { survival. }\end{array}$ \\
\hline
\end{tabular}

Note: R- rhizosphere soil; NR- bulk soil; CK- highly saline unplanted control soil. 

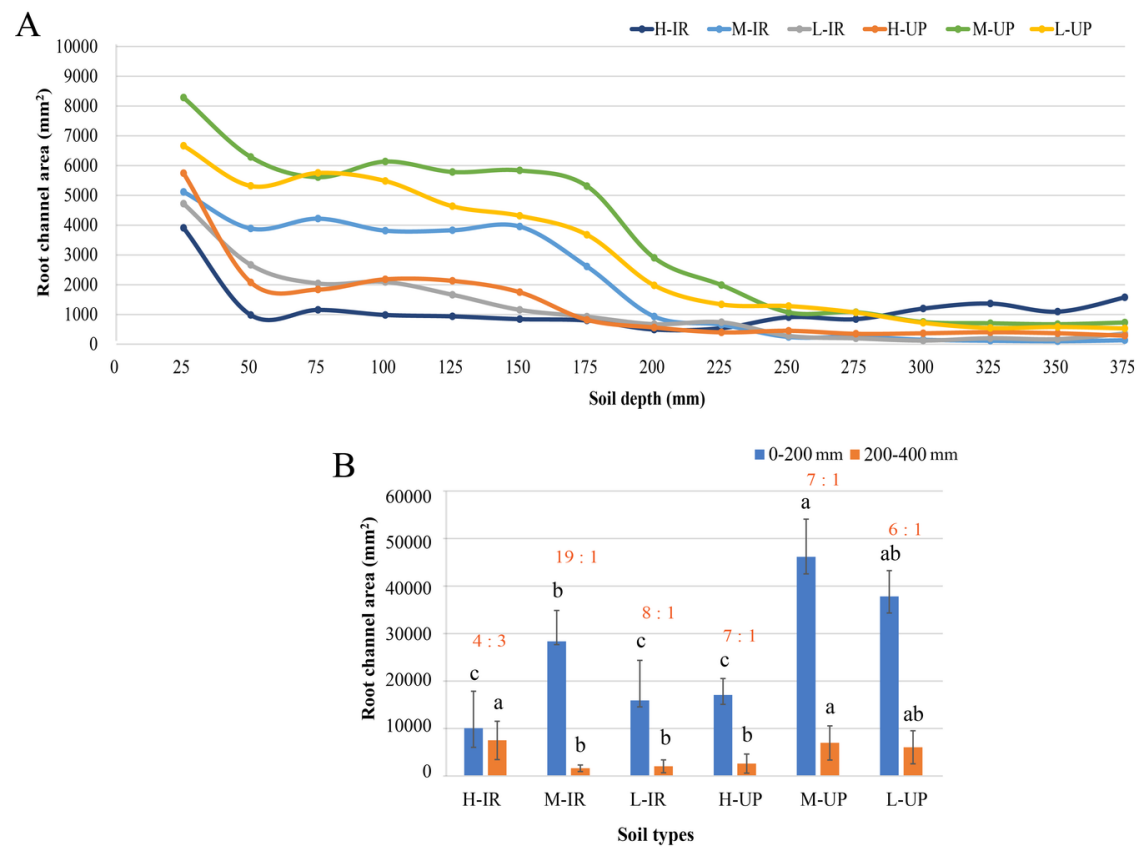
A

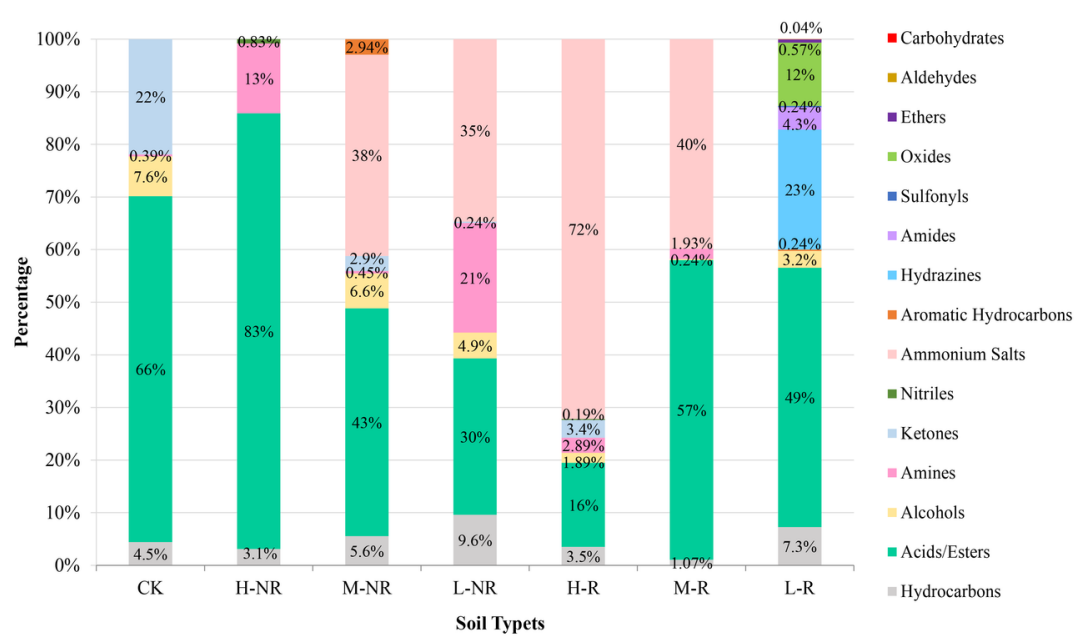

B

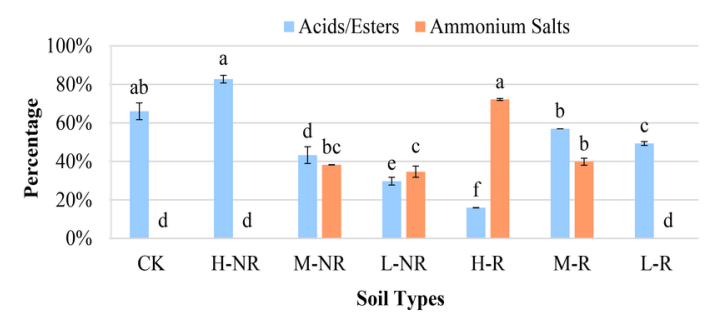

C

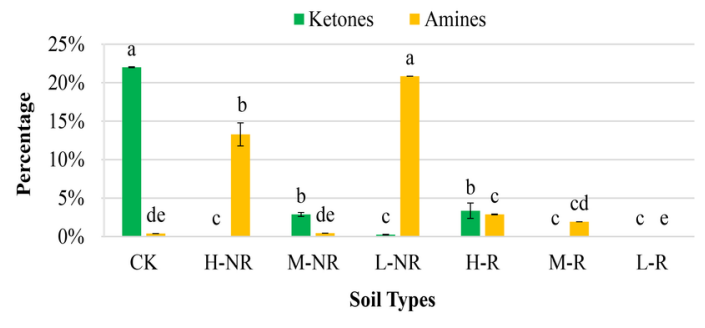

D

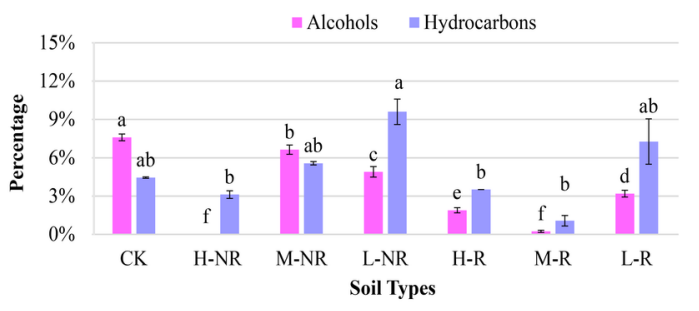



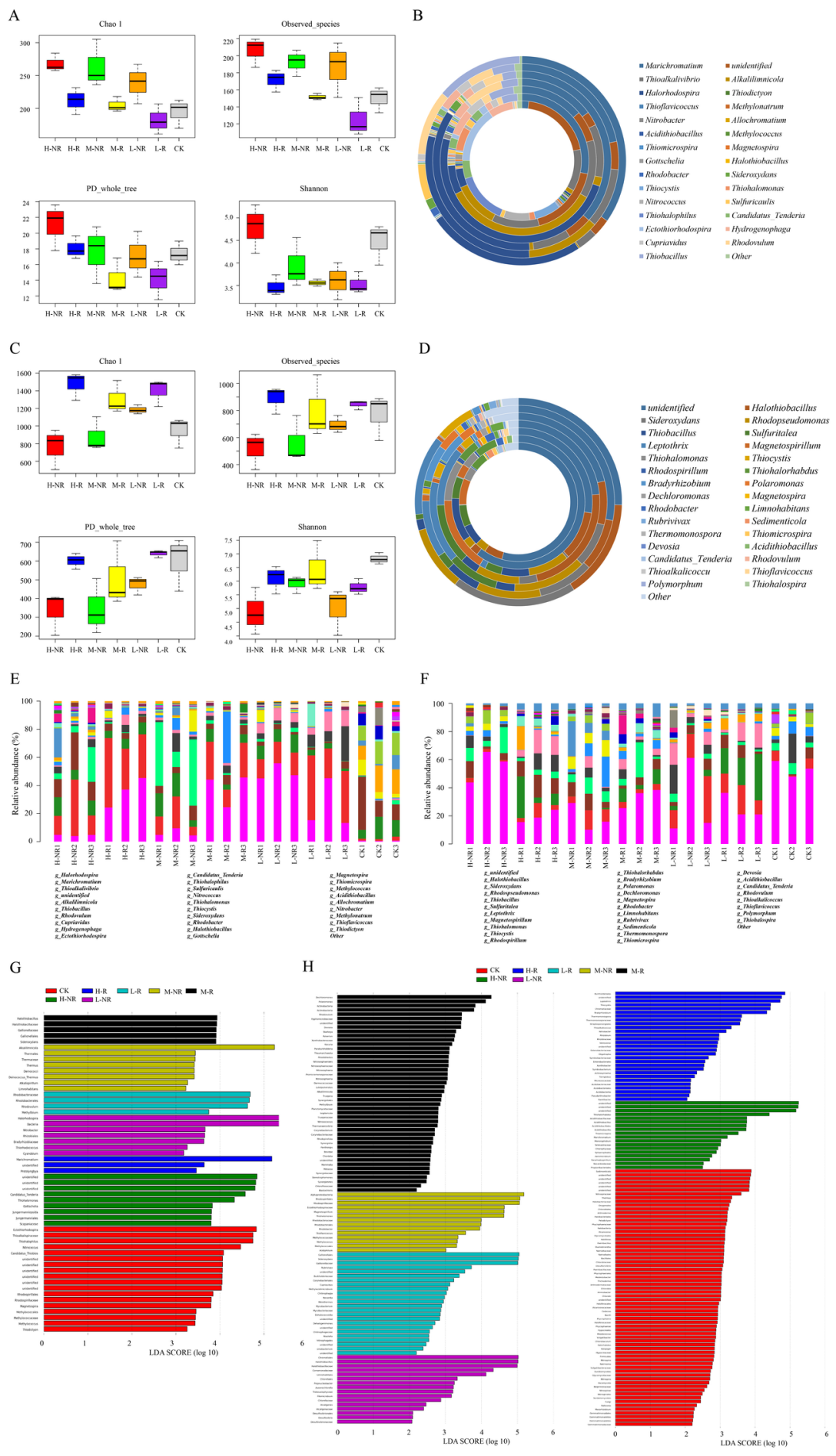
A
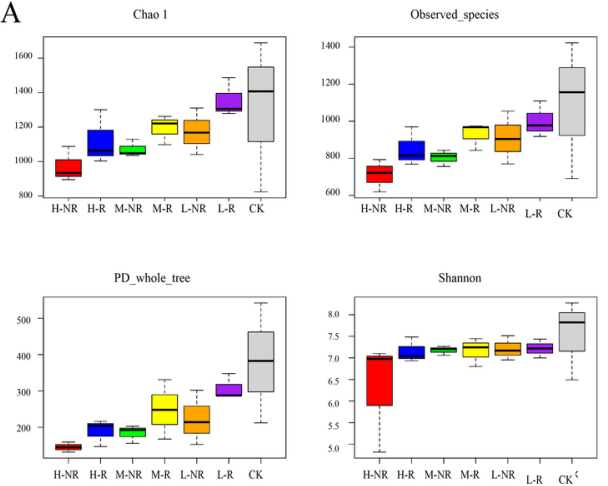

C
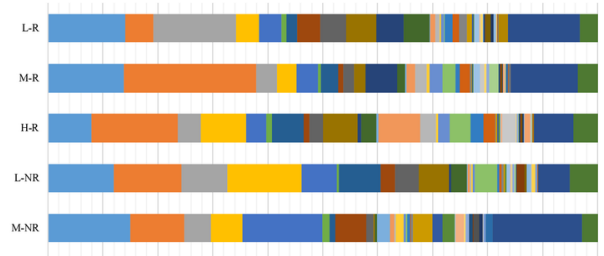

H.:R

CK

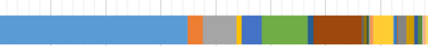

D

$\bar{D}_{\mathrm{H}-\mathrm{NR}}^{\mathrm{CK}} \bar{\sigma}_{\mathrm{L}-\mathrm{NR}}^{\mathrm{H} R}$

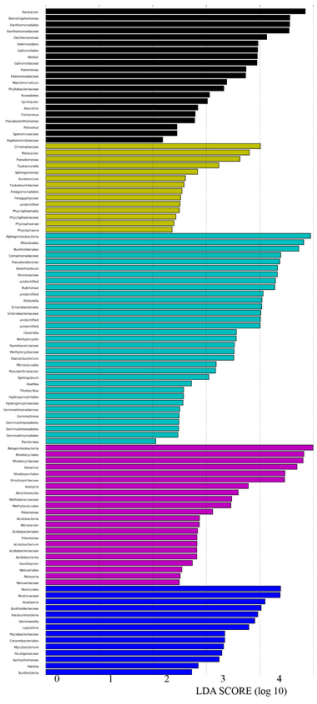

| | |

B

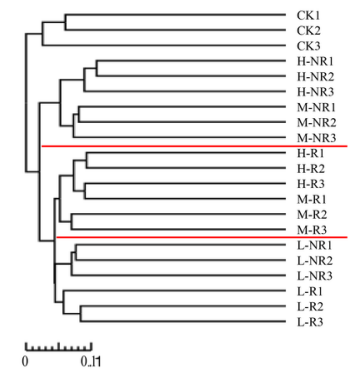

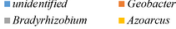

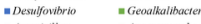

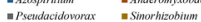

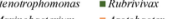

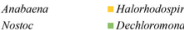

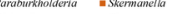

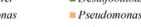

Leppotintix "Ralsoma

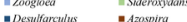

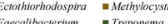

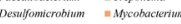

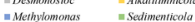

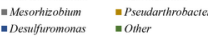

$$
\varpi^{\mathrm{L}-\mathrm{R}} \quad \square_{\mathrm{M}-\mathrm{NR}} \boldsymbol{\square}^{\mathrm{M}-\mathrm{R}}
$$

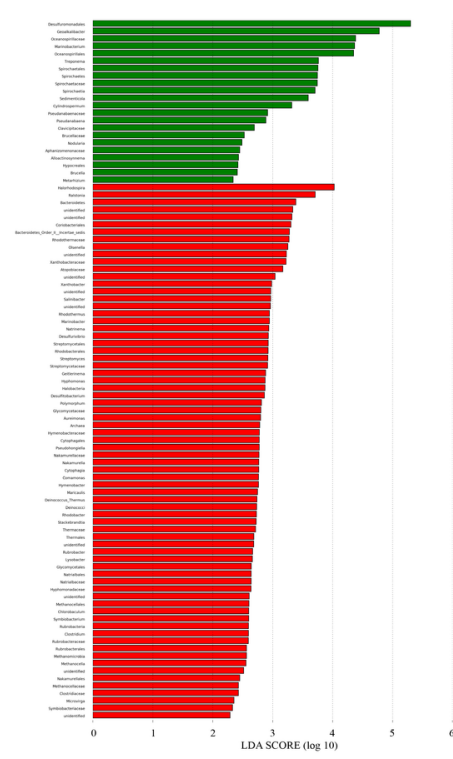




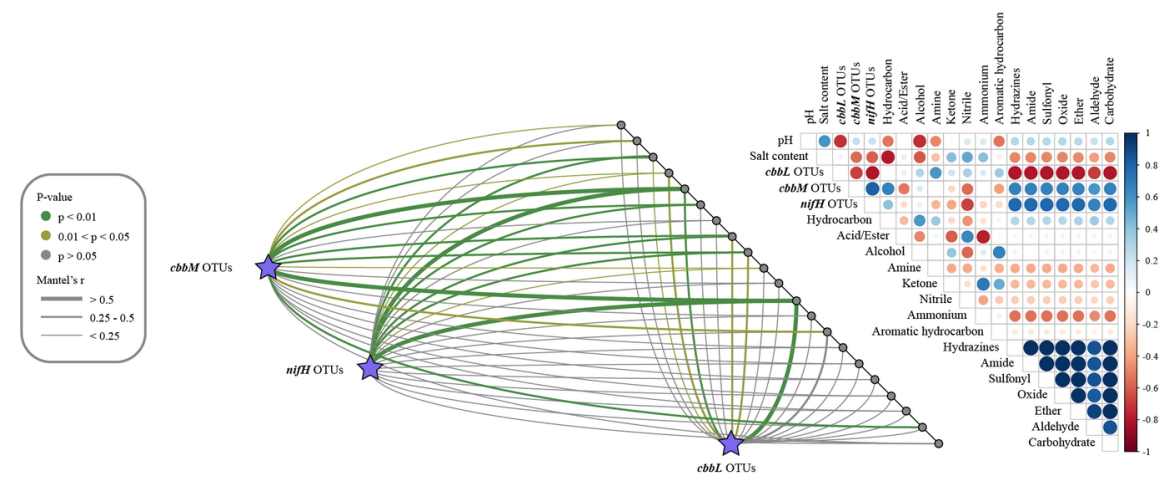

